\title{
LETTER
}

\section{Variability of reverse triggering in deeply sedated ARDS patients}

\author{
Jeremy Bourenne ${ }^{1 *}$, Christophe Guervilly², Malika Mechati ${ }^{1}$, Sami Hraiech² ${ }^{2}$ Megan Fraisse ${ }^{1}$, Magali Bisbal ${ }^{3}$, \\ Antoine Roch², Jean Marie Forel ${ }^{2}$, Laurent Papazian ${ }^{2}$ and Marc Gainnier ${ }^{2}$
}

(c) 2019 Springer-Verlag GmbH Germany, part of Springer Nature

Dear Editor,

Reverse triggering (RT) is an under-recognized form of patient-ventilator asynchrony detectable at the bedside [1, 2]. RT can promote ventilator-induced lung injury (VILI) by producing double triggering and stacked breaths resulting in an increase of tidal volume $(\mathrm{Vt})$ and transpulmonary pressure $\left(P_{\mathrm{L}}\right)$ [2]. Pendelluft contributes by inducing a redistribution of gas during RT leading to a local increase of $P_{\mathrm{L}}$. The aim of this study was the screening of RT phenomenon in deeply sedated, mechanically ventilated ARDS patients either receiving or not neuromuscular blocking agents (NMBA).

This is an ancillary physiologic study derived from a prospective randomized study [3]. We retrospectively analysed the continuous recordings of airway pressure, flow, volume and oesophageal pressure (Pes) over time in a subgroup of 21 ARDS patients ventilated with a $\mathrm{PaO} 2 /$ $\mathrm{FiO} 2$ ratio below $150 \mathrm{mmHg}$. Other inclusion criteria are detailed in the electronic supplementary material (ESM).

Oesophageal pressure measurements were performed via a specific nasogastric feeding tube (SmartCathG ${ }^{\circledR}$, VIASYS Healthcare, Palm Springs, CA, USA) equipped with an oesophageal balloon. Analysis was manually performed from the recordings using Acknowledge ${ }^{\mathrm{TM}}$ (Biopac) software by two intensivists (MM and MG). When RT was identified, the characteristics were analysed over the following 1-h period in order to describe its rate and duration.

\footnotetext{
*Correspondence: Jeremy.bourenne@ap-hm.fr

${ }^{1}$ Assistance Publique, Hôpitaux de Marseille, Hôpital Timone, Service de Médecine Intensive Réanimation, Réanimation des Urgences, Centre d'Études et de Recherche sur les Services de Santé et la Qualité de Vie, CEReSS, EA 3279, Aix-Marseille Université, Faculté de Médecine, Marseille, France

Full author information is available at the end of the article
}

For every patient and every recording in which we found the RT phenomenon, characteristics (frequency, entrainment ratio (ER), phase difference) were described or computed according to the methodology described by Akoumianaki et al. [2].

Continuous recordings of airway pressure, flow, volume and Pes were obtained in 21 moderate-to-severe ARDS patients (NMBA group, $n=11$; control group not receiving NMBA, $n=10$ ). Recording time totalled $10,920 \mathrm{~min}$ $(182 \mathrm{~h})$ in the NMBA group and $16,440 \mathrm{~min}(274 \mathrm{~h})$ in the control group. Sedation consumption is reported in the ESM.

No RT phenomenon was observed in the NMBA group. Three out of 10 patients (33\%) in the control group had evidence of $\mathrm{RT}(p=0.09)$. In this group, RT was observed during $0.33-17.88 \%$ of the $60 \mathrm{~min}$ of the analysis. Characteristics of RT for each patient are detailed in Table 1. Consequences on Vt and $P_{\mathrm{L}}$ depend on the time of respiratory cycle in which the RT occurs. The dominant pattern of entrainment was not stable (1/2, $1 / 3$ or minus).

Akoumianaki et al. [2] reported that RT observed in eight deeply sedated ARDS patients was characterized by a stable ER described as 1:1, 1:2 and 1:3. In our study, the ER was not stable. The major difference between the two studies is the duration of analysis i.e. $60 \mathrm{~min}$ vs $6-27 \mathrm{~min}$.

Inspiratory efforts generated by the RT caused ample variations of the level of lung pressures (delta Paw, plateau pressure, Pes and $P_{\mathrm{L}}$ ). We observed evidence of double triggering with stacked breaths leading to potential consequences: increase of the $P_{\mathrm{L}}$ and, consequently, the increase of stress and strain on the lungs leading to VILI $[4,5]$.

We confirmed the existence of RT in deeply sedated ARDS patients not receiving NMBA. Our study supports

\section{Springer}




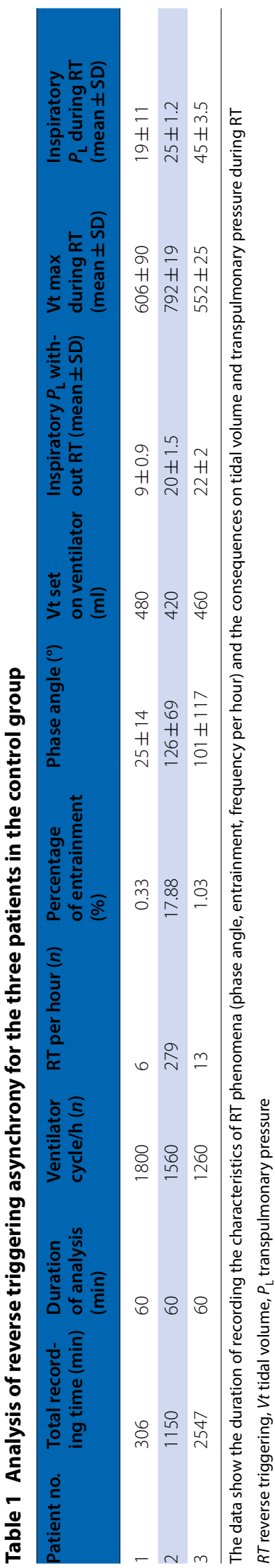

the experimental data of deleterious effects of strong spontaneous efforts in the early phase of severe ARDS.

\title{
Electronic supplementary material
}

The online version of this article (https://doi.org/10.1007/s00134-018-5500-6)

contains supplementary material, which is available to authorized users.

\begin{abstract}
Author details
${ }^{1}$ Assistance Publique, Hôpitaux de Marseille, Hôpital Timone, Service de Médecine Intensive Réanimation, Réanimation des Urgences, Centre d'Études et de Recherche sur les Services de Santé et la Qualité de Vie, CEReSS, EA 3279, Aix-Marseille Université, Faculté de Médecine, Marseille, France. ${ }^{2}$ Assistance Publique, Hôpitaux de Marseille, Hôpital Nord, Réanimation des Détresses Respiratoires et Infections Sévères, Centre d'Études et de Recherche sur les Services de Santé et la Qualité de Vie, CEReSS, EA 3279, Aix-Marseille Université, Faculté de Médecine, Marseille, France. ${ }^{3}$ Département d'Anesthésie-Réanimation, Institut Paoli-Calmette, 13009 Marseille, France.
\end{abstract}

\section{Compliance with ethical standards}

Conflicts of interest

The authors have no conflicts of interest.

\section{Ethical approval}

An approval by an ethics committee was not applicable.

\section{Publisher's Note}

Springer Nature remains neutral with regard to jurisdictional claims in published maps and institutional affiliations.

Accepted: 8 December 2018

Published online: 28 February 2019

\section{References}

1. Baconnier PF, Benchetrit $G$, Pachot $P$ et al (1993) Entrainment of the respiratory rhythm: a new approach. J Theor Biol 164:149-162

2. Akoumianaki E, Lyazidi A, Rey N et al (2013) Mechanical ventilationinduced reverse-triggered breaths: a frequently unrecognized form of neuromechanical coupling. Chest 143:927-938

3. Guervilly C, Bisbal M, Forel JM et al (2017) Effects of neuromuscular blockers on transpulmonary pressures in moderate to severe acute respiratory distress syndrome. Intensive Care Med 43:408-418

4. Yoshida T, Nakahashi S, Nakamura MAM et al (2017) Volume controlled ventilation does not prevent injurious inflation during spontaneous effort. Am J Respir Crit Care Med 196:590-601

5. Yoshida T, Nakamura MAM, Morais CCA et al (2018) Reverse triggering causes an injurious inflation pattern during mechanical ventilation. Am J Respir Crit Care Med 198:1096-1099 